\title{
pARTicipate: Art as Self-Expression for Persons with Aphasia (a Pilot Project)
}

Roujan Khaledan, Heather A. Tomlinson

\begin{abstract}
Aphasia is an acquired communication disorder resulting from a stroke or traumatic brain injury. Persons with Aphasia (PWA) have deficits in language comprehension and expression. Loss of communicative functions can be isolating for PWA as they may face barriers to accessing community-based leisure programs. Aphasia-friendly materials, visuals and simple written or oral instructions, can reduce such barriers and support communicative access. The pARTicipate project is a student-initiated art group that was piloted with the aim of encouraging PWA to trial an art class in a communicatively accessible and low-risk environment, as part of an outpatient rehabilitation program. By using a life participation approach for aphasia, this project aimed to promote participants' discovery, or rediscovery, of a hobby. Four PWA completed six art projects over 9 weeks. Communicative access was enhanced by using aphasia-friendly instructions and demonstrations to teach the projects. Participants showcased their projects and taught their skills to family and community members on the final "Share Day". Qualitative and quantitative data was gathered from satisfaction surveys. One hundred percent of the participants indicated that they enjoyed sharing their art with the community, and that they would join the group again if it was offered. Additionally, all participants indicated they would be likely to continue exploring art in the future. It is expected that the skills learned by PWAs in pARTicipate may help increase their confidence about participating in other community-based art classes. As well, continuing to use these skills may help participants develop a sense of belonging to the artistic community. By learning to incorporate personal symbols, PWA can be deliberate in their use of art for self-expression in the future. Finally, PWA were empowered to assume a leadership role during "Share Day". Having the opportunity to teach newly acquired artistic skills to their family and community members promoted positive feelings about the self and served to reveal their competencies.
\end{abstract}

Cite as: Khaledan R, Tomlinson HA. 2019. pARTicipate: Art as Self-Expression for Persons with Aphasia (a Pilot Project). Alberta Academic Review, Vol 2 (3) 10, CASCH Special Issue (not peer-reviewed), DOI: 10.29173/aar99. 